\title{
The Need for High Index of Suspicion in Early Diagnosis of Typhoid Fever in Young Children
}

\author{
${ }^{*}$ M.U. Amadife MBBS, FWACP, ${ }^{* *}$ F.E. Iyare MBBS, FMCPath, FICS \\ Department of *Paediatrics, ${ }^{* *}$ Histopathology, Ebonyi State University Teaching Hospital, \\ Abakaliki.
}

\begin{abstract}
ABSRACT
Background: The diagnosis of typhoid fever in young children is more difficult than in the adult due to the unusual pattern of presentation. This letter aims to sensitize general physicians and paediatricians on the need for a high index of suspicion in the diagnosis of typhoid fever in children.

Method: The case records of a child diagnosed with typhoid fever and a review of literature on the subject were used.

Result: A five year old female misdiagnosed as a case of severe malaria and sepsis was found to have typhoid fever on post mortem examination.

Conclusion: It is important to make an early diagnosis of typhoid fever in young children in order to prevent mortality from this treatable disease.
\end{abstract}

KEYWORDS: Typhoid fever; Early diagnosis; Children.

Paper accepted for publication 28th May 2006.

Early diagnosis of typhoid fever in young children is usually not easy because its pattern of presentation varies significantly from classical textbook description. We therefore report a case of a 7-month-old female infant who died after 4 hours of admission and a diagnosis of typhoid fever was made only at autopsy.

She was seen at the children emergency room of Ebonyi State University Teaching Hospital Abakaliki with a one-month history of vomiting. There was a past history of chronic diarrhea in early infancy. An elder sibling died at about the same age with a similar history. At the time of presentation, she was weak and restless and rapidly went into a hypovolemic shock. Terminally she developed generalized tonic-clonic seizures and died. The initial diagnosis was severe malaria to rule out septicemia. Resuscitation was commenced immediately.

We thought of the possibility of lactose intolerance as the cause of the chronic diarrhoea, but this could not be investigated because of her short stay in the emergency room. The only available results were packed cell volume of $32 \%$, white cell count of $8.4 \times$ $10^{9} / \mathrm{L}$, erythrocyte sedimentation rate of $76 \mathrm{~mm}$ in the $1^{\text {st }}$ hour, serum bicarbonate of $18 \mathrm{mmol} / \mathrm{L}$, potassium of $1.5 \mathrm{mmol} / \mathrm{L}$. No malaria parasite was seen in the blood film.

Post mortem examination revealed many and markedly enlarged mesenteric lymph nodes and peyer's patches. On microscopy, the mesenteric lymph nodes and peyer's patches showed polymorphous infiltrates of mononuclear cells with few showing erythrophagocytosis. (See Fig. 1).

Typhoid fever is rare in those less than 5 years and presents with non specific signs and symptoms such as vomiting, diarrhoea and or cardiovascular shock ${ }^{1-3}$. The most definitive method of diagnosis of typhoid fever is by isolation of the organism (salmonella enterica serotype typhi) from blood or bone marrow ${ }^{4}$. The widal test is the most commonly used test in the diagnosis of typhoid fever in Nigeria and is often overused and misinterpreted ${ }^{1}$. However in this patient neither blood cultures nor Widal tests were done because typhoid fever was not suspected at the time of presentation and on account of her very short stay in the emergency room. Johnson and Aderele in Ibadan reported that only $58 \%$ of cases of typhoid fever in young children were correctly diagnosed clinically. The finding of infiltration of tissue macrophages containing bacteria is taken as the hallmark histologic finding in typhoid fever ${ }^{5}$, and the findings in this case were consistent with typhoid fever. Therefore it is of paramount importance to have a high index of suspicion in young children who present with the symptoms described in our patient, to make early diagnosis of typhoid fever in children of this age group.

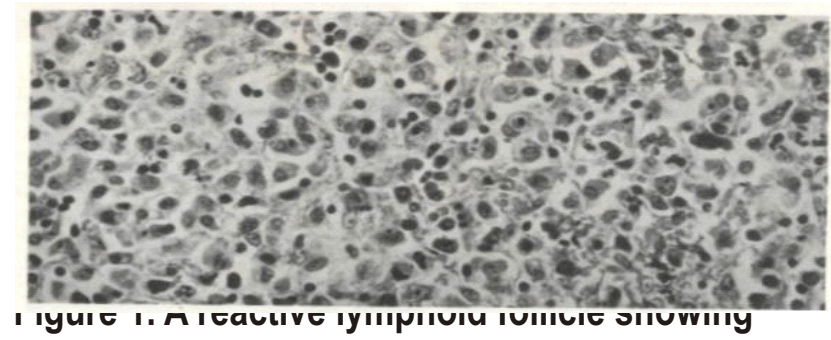

polymorphous infiltrates of mononuclear cells. Some of the cells show erythrophagocytosis.

\section{REFERENCES}

1. Katung PY. A brief review of typhoid fever in Nigeria. Nigerian medical practitioner 2000;38:4-6. 
2. Johnson AOK, Aderele WI. Enteric fever in childhood. Journal of Tropical Medicine and Hygiene 1981; 84: 29-35.

3. Ferreccio C, Levine MM, Manterola A, et al. Benign bacteraemia caused by salmonella typhi and paratyphi in children younger than 2 years. J Pediatr 1984; 106 : 899-901.
4. Cleary TG. Enteric fever In: Behrman RE, Kliegman RM, Jenson HB (Eds). $16^{\text {th }}$ ed. Nelson Text book of Paediatrics. Philadephia. WB Saunders Company 2000: 845-8.

5. Cotran, Kumar, Robbins. Robbins pathologic basis of disease $4^{\text {th }}$ edition. Philadelphia. W. B Saunders company. 353 - 354 . 


\section{NARD AGM 2006}

The Annual General Meeting and Scientific Conference (AGM) of the National Association of Resident Doctors of Nigeria (NARD) takes place in Enugu from the $20^{\text {th }}$ to $24^{\text {th }}$ September 2006. The AGM is being hosted by the University of Nigeria Teaching Hospital (UNTH) Enugu branch of the Association. The main theme of the conference is "Challenges of Cardiovascular Surgery in a developing Nation". Futher enquiries on the conference can be sourced from the local organising committee (LOC) through the following email addresses echrischukwu@yahoo.com , uojinmah@yahoo.com and the following phone numbers 08033423804 and 08053308472.

\section{NARD ANNUAL LECTURE HOLDS}

The annual lecture series of the National Association of Resident Doctors (NARD) took place in Calabar on the $28^{\text {th }}$ of July 2006. The lecture titled "Managing Medical Migration and building equitable health systems" was delivered by Dr N E Udonwa a Consultant Family Physician and Chairman Medical Advisory Committee of the University of Calabar Teaching Hospital. The lecture was well attended. 


\title{
Multiple Choice Questions In Dermatology
}

\author{
Answer True (T) or False (F) \\ D. D. Altraide MBBS, FWACS \\ Department of Medicine University of Port Harcourt Teaching Hospital , Port Harcourt, Nigeria.
}

1. Kobner phenomenon occurs in the following
a vitiligo
b scabies
c Lichen planus
d Warts
e Psoriasis

2. The turn over period for keratinocytes is
a 6 weeks
b 2 weeks
c 4 weeks
d 1 week
e 10 weeks

3. Seborrheic dermatitis
a response to topical antibiotic therapy is satisfactory
b Is synonymous with napkin dermatitis
c responds to treatment with topical ketoconazole
d Is a harbinger of atopic dermatitis
e may cause a cradle cap

4. Molluscum contagiosum
a Is not largely a disease of adults
b Lesions 'are characterized by central umblication
c The face is the least favoured site
d It can occur as a venereal disease
e Is a viral disease

5. Langerhans cells of the skin
a play a role in the synthesis of vitamin $D$
b Are involved in phagocytosis
c Presentation of antigen to $T$ lymphocytes
d Vitamin $\mathrm{C}$ synthesis
e Helps in regulation of body fluid loss

6. In the urethral discharge syndrome
a A gram stain is necessary before treatment can be commenced
b Ureaplasma urealyticum is a causative agent
c Tinidazole is in a dose of $500 \mathrm{mg}$ is appropriate treatment
d The 4Cs are an essential part of the management
e Erythromycin is the antibiotic of choice

7. The pruritic papular eruption seen in HIV
a Is treated with topical steroids and antibiotics
b Phototherapy is useful in its treatment
c Distribution of lesions is usually symmetrical
d Is due to a direct effect of the HIV virus
e Occurs only in patients with slims disease

8. The following nail changes are seen in psoriasis
a onycholysis
b thimble pitting
c Beau's lines
d subungal hyperkeratosis
e koilonychias

9. In genital ulcer disease
a The syphilitic chancre is usually accompanied by a bubo
b Donovanosis is a cause of recurrent lesions
c Oral acyclovir is the treatment of choice for herpes simplex
d Benzathine peniciliin given ina single dose is the treatment of choice
e Lymphogranuloma venerum presents at the stage of the bubo with an ulcer

10. Itchy scaling lesions on the back with the Christmas tree appearance is diagnostic of
a Icthyosis
b Lichen planus
c Tinea vesicolor
d Pityriasis rosea
e Guttate psoriasis 